\title{
Priming autonomous and controlling motivation and effects on persistence
}

\author{
Stephen L. Murphy ${ }^{1}$ (D) lan M. Taylor ${ }^{2}$ \\ Published online: 14 July 2020 \\ (C) The Author(s) 2020
}

\begin{abstract}
The present studies examined whether priming distinct motivational states influenced persistence at a task designed to promote repeated failure, and post-task plans for engaging in self-regulatory activity. Two double-blind, between-subject experiments (Study 1: $N=58$; Study 2: $N=92$ ) involved participants being randomized to Autonomous Motivation, Controlling Motivation, or Neutral prime conditions using a scrambled-sentence test. Participants then attempted an impossible persistence task that promoted repeated failure. Following, participants reported their plans to engage in exercise. Using frequentist and Bayesian analyses, Study 1, Study 2, and an internal meta-analysis showed no differences in persistence or planned exercise across priming conditions, thus contrasting with previous research. Unanticipated moderation effects or motivational priming effects being smaller than those inputted into a priori power analyses may be the most likely reasons for these findings.
\end{abstract}

Keywords Motivation $\cdot$ Priming $\cdot$ Persistence $\cdot$ Autonomy $\cdot$ Self-determination

\section{Introduction}

Persisting in a course of action despite difficulty or opposition represents a crucial characteristic for success in life, including high academic achievement, good physical and psychological health, and relatively higher earnings (Duckworth et al. 2007; Heaven and Ciarrochi 2008; Moffitt et al. 2011). Despite these benefits, many individuals do not persist with their goals, choosing instead to respond to set-backs or difficulties by quitting (Marlatt and Donovan 2005) or opting for easier options. Responding to difficulties by dispensing with a goal may occasionally have value (Ntoumanis et al. 2014a), but desistance can also be maladaptive. For instance, responding to difficulties by giving up on health goals can lead to insufficient physical activity or a poor diet (Cappelli and Mobley 2017; Sallis et al. 2016). Therefore, it is of interest to identify factors which may facilitate persistence. The aim of this research was to explore persistence and desistance from a motivational perspective.

Stephen L. Murphy

Stephen.murphy@ruhr-uni-bochum.de

1 Department of Social Psychology, Faculty of Psychology, Ruhr-University Bochum, Universitätsstraße 150, 44801 Bochum, Germany

2 School of Sport, Exercise \& Health Sciences, Loughborough University, Epinal Way, Loughborough LE11 3TU, UK
Self-determination theory (SDT; Ryan and Deci 2017) is highly relevant for understanding the motivational processes driving persistence and desistance. Specifically, SDT maintains persistence in an activity should be more prevalent when individuals' reasons for engagement are more greatly endorsed by, or in line with, their overarching self (i.e., individuals' reasons for engagement are more/less autonomous/controlling). Thus, individuals who engage in an activity for reasons indicative of high endorsement, e.g., because they find it fun or due to its identified benefits, would be regarded by SDT as being more likely to persist than individuals who engage in an activity for reasons indicative of low endorsement, e.g., to avoid feeling guilty, to protect their contingent self-esteem, or due to external pressures. The basis proposed for this effect is that individuals, fundamentally, have more to gain from being persistent when they are more, rather than less, autonomously motivated (Ryan and Deci 2017). For instance, individuals motivated for more autonomous reasons (i.e., less controlling reasons) are more likely to experience enhanced perceptions of autonomy, competence, and relatedness during engagement (Milyavskaya and Koestner 2011), experiences of which have clear motivational impetus (Berkman et al. 2017; Ryan and Deci 2017), and are ubiquitously referred to as psychological needs within SDT given their positive link with wellbeing (Ryan and Deci 2017). It thus follows 
that, upon exposure to situations of adversity or failure, more autonomously motivated individuals would have greater reason to persist and to recruit the necessary cognitive, affective, and energetic resources to do so (Ryan and Deci 2017).

Much observational (Pelletier et al. 2001; Vallerand et al. 1997) and experimental (Legault and Inzlicht 2013; Moller et al. 2006) evidence demonstrates a positive link between autonomous motivation and persistence, thus supporting SDT tenets. Most observational evidence comes from research showing motivation to explain continued engagement over long periods of time (i.e., where drop-out represents a distinct possibility), its relevance being that difficulties and set-back become inevitable over prolonged periods of months or years. For instance, autonomous motives (i.e., motives characterized by a sense of wanting to do an activity) positively predicted engagement in sport and swimming 12 (Jõesaar et al. 2011) and 22 (Pelletier et al. 2001) months later, respectively, while controlling motives (i.e., motives characterized by a sense of having to do an activity) were either unpredictive or negatively predictive of swimming engagement (Pelletier et al. 2001). Ample evidence also demonstrates distinct motivational states explain the adoption of coping strategies that are likely to be critical determinants of long-term persistence (Ntoumanis et al. 2009). For instance, when dealing with adversity during goal pursuit, autonomous motives increase the likelihood plans will be made to overcome adversity, and that social support will be sought (Gaudreau et al. 2012; Smith et al. 2011). Controlling motives, in contrast, positively predict the likelihood that individuals will give-up when adversity arises during goal pursuit (Gaudreau et al. 2012). Experimental evidence, which often draws from research exposing participants to difficulty or set-back during brief activities, is similarly supportive of SDT tenets. For instance, participants engaged in tasks designed to elicit repeated failure were found to perform better (Legault and Inzlicht 2013) and engage for longer (Moller et al. 2006) if initially given a choice of which task to engage in (a strategy known to promote more autonomous involvement), relative to being pressured into engaging in a specified task (a strategy known to promote more controlling involvement).

Although extant literature supports SDT tenets that individuals' motives for an activity associate with, and cause, differences in persistence, it would also be of interest to establish whether priming motivation may prove similarly effective in influencing persistence. Priming refers to activating an individual's cognitive structures, usually outside of their awareness, with the aim of influencing their thoughts, feelings or behavior (Cameron et al. 2012). Therefore, priming specific motivational states is distinct from more explicit manipulations, the likes of which have been shown to promote persistence (e.g., increased task choice; Moller et al. 2006), in that primes are situationally much less focal and less likely to be regarded by individuals as giving rise to specified outcomes. Priming effects are believed possible because the mind is organized in associative networks, therefore activating a particular concept will trigger connected notions (Bargh 2013). Thus, even minimal exposure to the concept 'autonomous motivation', for instance, through words inextricably linked to more autonomous functioning (e.g., 'freedom', 'volition', 'choice'), or individuals that exude this sense of being autonomously motivated (e.g., Ntoumanis et al. 2014b), should be sufficient to activate cognitive structures that orient individuals, at least to a small extent, to be more likely to think, feel or behave in ways indicative of being more autonomously motivated (e.g., Levesque et al. 2008).

Establishing whether motivational primes influence persistence is of interest for various reasons, not least because priming strategies would enhance the motivational 'toolbox' available to practitioners. Autonomous motivation primes would prove particularly useful in situations where the use of more explicit motivational interventions is impractical. For instance, providing exercisers with choice and a rationale for doing exercise in a gym environment may well be able to enhance persistence via elevated autonomous motivation (Ryan and Deci 2017), however, such explicit interventions often require the use of fitness instructors whom are frequently not available in numbers sufficient to be effective. Priming interventions, in contrast, perhaps in the form of posters, billboards, or videos displayed within the gym environment, would be practical to use in this and similar situations, particularly considering they usually have minimal (or no) dependency upon personnel, and can remain in place longterm at low cost. Establishing whether motivational primes influence persistence would also inform practitioners of situational factors which may hinder persistence for select exercisers due to their controlling features (e.g., a poster stating 'don't give up!'), thus leading these situational components to be exchanged (or removed) to suit the target population. Finally, investigating whether motivational primes influence persistence would prove valuable given priming modalities would provide a more robust test of SDT tenets that promoting change in motivation will bring about differences in persistence. Indeed, although extant literature using explicit manipulations consistently demonstrate the motivation-persistence relationship (e.g., Legault and Inzlicht 2013; Moller et al. 2006), the relatively homogenous nature of the methodological approach used by these and similar studies cannot discount the possibility that oft-adopted methodological factors unrelated to the declared manipulation may, at least in part, explain these effects.

Research indicates the ability to effectively intervene with priming modalities may represent a greater challenge than initially thought, with an increasing number of failed replications of previously established non-motivation related priming effects being reported (e.g., Harris et al. 2013; Shanks et al. 2013). Nevertheless, the large body of research consistently demonstrating motivational primes to promote theoretically 
congruent outcomes suggests that priming motivational states represents a distinct possibility. For instance, relative to controlling motivation primes, exposing individuals, either subliminally (i.e., outside of participants conscious awareness) or supraliminally (i.e., where participants are consciously aware of the primes presence but not its function), to words or people associated with the concept 'autonomous motivation' led to increased self-reported autonomous engagement (Levesque and Pelletier 2003; Radel et al. 2009; Scarapicchia et al. 2013). Relative to controlling motivation and/or neutral primes, autonomous motivation primes have also promoted various outcomes conceptually indicative of more autonomous involvement, including increased levels of enjoyment (Banting et al. 2011; Brown et al. 2016), higher implicit selfesteem (Hodgins et al. 2007), reduced levels of defensiveness (Hodgins et al. 2006; Hodgins et al. 2010), more adaptive emotional expression (Weinstein and Hodgins 2009), and higher levels of creativity (Weinstein et al. 2010). This evidence implies that, relative to a neutral prime, autonomous motivation primes will enhance individuals' tendency to persist at activities that expose them to set-back or adversity, while controlling motivation primes will hinder persistence.

Indeed, there is direct support for this notion, with motivational primes found to influence persistence in three studies (Keatley et al. 2014; Ntoumanis et al. 2014b; Radel et al. 2009). In the first of these (Radel et al. 2009), participants subliminally exposed to words inextricably tied to autonomous functioning performed more effectively, and for longer, at a tiring physical task relative to participants subliminally exposed to words inextricably linked to heteronomous functioning (i.e., controlling motivation). The second study reported similar priming effects across these conditions but in an athletic population (Ntoumanis et al. 2014b). Here, participants viewed a video of a confederate either exhibiting controlling motivation (controlling motivation prime) or autonomous motivation (autonomous motivation prime) for an upcoming task, or describe a task used in an unpublished imagery effectiveness study (neutral prime), prior to engaging in a very challenging cycling task. Results showed participants that received the neutral prime completed more stages of this cycling task relative to participants that received a controlling motivation prime but completed less stages relative to autonomously primed participants. Finally, in the third study participants that completed a scrambled-sentence task (which requires that words are re-ordered to make grammatically incorrect sentences grammatically correct) containing words inextricably tied to autonomous functioning (autonomous motivation prime) made more attempts of a geometric task that, unbeknownst to them, was impossible to solve, relative to participants that completed a scrambled-sentence task containing words that were either indicative of controlling motivation (controlling motivation prime) or not indicative of a distinct motivational state (neutral prime; Keatley et al. 2014). Together, these studies demonstrate a consistent trend in line with SDT tenets that priming distinct motivational states influences the ability of individuals to overcome failure and set-back.

Nonetheless, because the experimenters in two of these three studies (i.e., Keatley et al. 2014; Ntoumanis et al. 2014b) were not blind to participant condition, this research is insufficient for confirming motivational primes do indeed influence persistence. Blinding experimenters to participant condition may seem like a minor concern. However, research demonstrates experimenters, when aware of participant condition, may subconsciously modify their behavior such that effects manifest in line with their expectations (Doyen et al. 2012; Gilder and Heerey 2018). Furthermore, this same research shows that when experimenters were made blind to participant condition, previously well-established priming effects could not be identified (Doyen et al. 2012). Thus, in these two motivational priming studies, it remains unknown whether the reported differences in persistence across conditions resulted due to the priming manipulation or to subconscious experimenter biases brought on by this awareness of participant condition. Considering only three studies to our knowledge demonstrate evidence that motivational primes are effective in influencing persistence, and two of these did not blind experimenters to participant condition, it is clear further research is required to elucidate whether this effect exists. Accordingly, the aim of the present research is to contribute in this regard and examine whether priming autonomous motivation promotes persistence relative to a neutral prime, and whether priming controlling motivation hinders persistence, while ensuring experimenters remain blind to participant condition. The priming manipulation and measure of persistence used by Keatley et al. (2014) are ideal for testing these effects, therefore we adopted a highly similar priming manipulation and the same measure of persistence. Thus, Study 1 can be considered an attempt at replicating the findings of Keatley et al. (2014).

More autonomous involvement often renders an activity easier and less cognitively depleting (Milyavskaya et al. 2015; Werner et al. 2016). This raises the possibility that autonomously and heteronomously primed individuals (relative to individuals that are not primed) may have more and less energy for cognitively taxing activities after persistencerequiring activity is finished, respectively (Berkman et al. 2016; Hagger et al. 2010), a capacity that research indicates may be critical for continued self-regulation. For instance, planning represents an important self-regulatory tool which itself requires self-regulation to use (i.e., planning requires effortful control over thoughts and the mental construction of steps from present to a future goal state; Sjåstad and Baumeister 2018), however, cognitive fatigue has been shown to reduce individuals inclinations to make immediate plans (Sjåstad and Baumeister 2018), plans less certain of being effectively actioned (Lyu et al. 2017), or exercise plans for the following day (Rebar et al. 2018). While research confirms 
more autonomous involvement in a persistence-requiring activity aids performance in a subsequent activity that requires self-regulation (i.e., a handgrip endurance task; Muraven et al. 2008), it has yet to be established whether priming distinct motivational states may elicit similar effects. Furthermore, research demonstrating motivational primes to influence plans to engage in exercise did not follow a persistence-requiring task (Banting et al. 2011; Magaraggia et al. 2014). Thus, a secondary aim of the present research is to examine whether, relative to a neutral prime, an autonomous motivation prime enhances the plans participants make to engage in activity following a persistence-requiring task, and whether a controlling motivation prime attenuates these plans.

\section{Present Studies}

Two experimental studies were conducted to examine whether an autonomous motivation prime enhanced persistence during a geometric task designed to elicit repeated failure (relative to a neutral prime), and whether a controlling motivation prime hindered persistence. This is an attempt at replicating previous findings (Keatley et al. 2014), therefore, we similarly hypothesized that priming participants to experience autonomous/controlling motivation would increase/decrease persistence on the geometric task relative to the neutral prime (hypothesis 1). In addition, we investigated whether any anticipated effects in the first phase would influence participants plans to engage in exercise, hypothesizing that participants in the autonomous/controlling condition would plan more/less exercise, relative to a neutral condition (hypothesis 2). In both studies presented in this paper, we report how we determined our sample size, all data exclusions (if any), all manipulations, and all measures in the study according to the recommendations made by Simmons et al. (2012). All data and materials used in the current studies are posted on the Open Science Framework (https://osf.io/9r7qb/?view_only= 6f29dad2396544c2a3c9e46fe0b12a31).

\section{Study 1}

\section{Methods}

Participants With a power of .80, an alpha of .05, and a threegroup design, $\mathrm{G}^{*}$ Power (Faul et al. 2007) estimated 66 participants were required to identify a large effect $(f=.40)$. This sample size was the target; however, we also considered the very large effects obtained in previous work (equivalent $f>1$; Keatley et al. 2014) and the practical costs of recruiting more participants. In total, fifty-eight participants (Mean age $=$ 21.31 years, $S D=5.3$ years; 39 female) were recruited to this study from the general public and from Psychology classes at a university in the United Kingdom. Students recruited from
Psychology classes were offered course credit for their participation. Ethical approval was granted by the University Ethics Committee prior to study commencement.

Procedure Participant consent was obtained before testing. The experimenter necessarily misinformed participants that the study aim was to explore the link between cognitive ability and exercise behavior. Prior to their session, participants reported their typical exercise levels to rule out differences across groups (see Self-Report Measures for more details). Upon arrival for their session participants recorded their age and gender (for descriptive purposes). Participants also recorded their mood to rule out differences across groups (see Self-Report Measures section), for differences in mood may explain to what extent individuals will persist (Hagger et al. 2010). Participants were then familiarized with a geometric problem-solving task taken from Baumeister et al. (1998). This required they trace the lines of a geometric figure without retracing any lines or lifting their pencil from the paper. Multiple attempts were permitted for each of two solvable figures until they were solved, or ten minutes had elapsed.

To commence the experimental manipulation, participants were then handed the Scrambled-Sentence Test (SST; Srull and Wyer 1979) and misinformed it represented a measure of language ability. Rather, this test served to prime participants to think, feel, and behave in condition-relevant ways. Pilot testing conducted prior to this study suggested participants were unlikely to identify with the SST's actual purpose. The SST consisted of twenty-four grammatically incorrect sentences containing five words (e.g., there, now, is, forget, it). Participants were required to reconstruct the sentences to make them grammatically correct by using any four of the five words (e.g., it, is, there, now).

Three versions of the SST were constructed to prime individuals to experience autonomous motivation, controlling motivation, or a neutral prime, respectively. For the autonomous and controlling conditions, twelve of the twenty-four items contained a word semantically congruent with the respective condition. The words incorporated into the sentences were also similar to those used in previous motivational priming research (Keatley et al. 2014). Prior to the study, four researchers with knowledge of SDT rated the extent to which they believed the collection of words related to controlling and autonomous motivation, respectively (on a 7-point Likert scale ranging from ' 1 - not true at all' to '7 - very true'). Autonomous words were given a mean score of 5.52 and the controlling words given a mean rating of 5.25, indicating that the words had face validity. For the controlling condition, the priming words used were: pressured, coerced, forced, manipulated, obliged, prevented, controlled, pushed, repressed, compelled, constrained, and restrained. For the autonomous condition, the priming words used were: volitional, authentic, valued, engaged, autonomous, voluntary, choice, free-will, intrinsic, freedom, optional, and internally. For the 
neutral condition, the priming words used were: ready, athletic, coming, distracted, asleep, useful, intelligent, taught, consistent, hot, understandable, and normal.

Participants first read the SST instructions provided, and then completed two practice sentences, which were checked for accuracy to ensure participants understood the task. If mistakes were made participants were shown an example solution. Participants were randomized to an experimental condition ( $n$ per condition; Aut Mot: 20, Con Mot: 19, Neut: 19) and were informed they were to complete all twenty-four sentences as quickly and accurately as they could, and to press a bell upon completion. The SST was presented to participants inside an envelope so the experimenter remained blind to their experimental condition. Any participants having not completed the SST within a fifteen-minute period were stopped by the experimenter. Given explicit manipulation checks may attenuate, enhance, or interact with the manipulation (Hauser et al. 2018), and literature demonstrating near-identical motivational manipulations to promote distinct motivational states (Banting et al. 2011; Hodgins et al. 2006), a manipulation check was not utilized in the present study.

Immediately after the SST, participants attempted to complete two figures of the geometric tracing task, however, unbeknownst to participants these figures were impossible to solve. The following instructions were read aloud to participants verbatim prior to beginning the task:

'You can take as much time and as many trials as you want. You will not be judged on the number of trials or the time you will take. You will be judged on whether or not you finish tracing the figures. When you have completed the task, press the bell to get my attention. However, if you feel like you are unable to complete the task, you may also press the bell.'

The duration participants spent on this task represented a measure of persistence. In line with previous research (Baumeister et al. 1998) any participants reaching forty minutes were stopped by the experimenter. Participants then completed a self-report questionnaire to record their exercise plans during a typical week (see Self Report Measures section) and were fully debriefed on the study's true aim and thanked for their participation.

\section{Self-Report Measures}

Typical Exercise Behavior Each participants' typical level of exercise behavior was measured using the Godin LeisureTime Exercise Questionnaire (GLTEQ; Godin and Shephard 1985). This measure included the stem 'During a typical 7-day period (a week), how many times on the average do you do the following kinds of exercise for more than 15 minutes during your free time?'. Participants recorded the number of sessions that were strenuous, moderate, and mild. The number of sessions at each intensity were then multiplied by their metabolic equivalent $($ MET) value (strenuous $=9$, moderate $=5$, mild $=$ 3 ), and summed for an overall exercise behavior value. This questionnaire is reliable and has been validated against physical fitness assessments showing higher ratings on the scale to positively correlate with $\mathrm{VO}_{2 \max }$ performance, and to negatively correlate with percentage body fat (Godin and Shephard 1985).

Mood The pleasant/unpleasant subscales of the valid and reliable Brief Mood Introspection Scale (BMIS; Mayer and Gaschke 1988) were used as a measure of mood. Participants rated 16 items relevant to their current mood on a 4-point Likert scale ranging from 1 ('definitely do not feel') to 4 ('definitely feel'). An overall mood score was calculated by subtracting the summed score of the unpleasant subscale ( 8 items) from the summed score of the pleasant subscale ( 8 items).

Planned Exercise Behavior Each participant's planned level of exercise behavior was measured using the GLTEQ with a modified stem: 'During a typical 7-day period (a week), how many times do you plan on doing the following kinds of exercise for more than 15 minutes during your free time?'. The remainder of the questionnaire and procedure was identical to the measure of typical behavior.

\section{Results}

Analyses were conducted using the frequentist Null Hypothesis Significance Testing (NHST) approach with SPSS software version 24. To also examine the likelihood of an effect being absent (which NHST is unable to do; Quintana and Williams 2018), Bayes factors, which provide credibility estimates for the null and alternative hypothesis, were additionally calculated for all examined effects (using JASP statistics package version 0.10 (available online at https://jaspstats.org/)). Prior model probabilities should remain at default in lieu of substantial knowledge of the underlying statistical framework (Wagenmakers et al. 2018). Accordingly, the Caucy default prior of $r=0$. 707 was utilized for all Bayesian analyses.

Mean scores across conditions are displayed in Table 1. Preliminary Analysis using one-way ANOVA found no significant differences for mood, $F(2,55)=.12, p=.89$, SST duration, $F(2,55)=.47, p=.63$, or typical exercise behavior, $F(2,55)=.26, p=.77$, across conditions. Bayesian analyses support these findings, with data 6.63 (mood), 5.13 (SST duration), and 5.97 (typical exercise behavior), times more credible under the null than the alternative hypothesis. Twelve participants $(20.7 \%)$ persisted for the full 
Table. 1 Mean scores of study variables across conditions in Study 1 ( $95 \%$ confidence interval $[ \pm]$ included in brackets)

\begin{tabular}{lllc}
\hline & $\begin{array}{l}\text { Controlling } \\
\text { Motivation }(n=19)\end{array}$ & $\begin{array}{l}\text { Autonomous } \\
\text { Motivation }(n=20)\end{array}$ & Neutral $(n=19)$ \\
\hline Mood (potential range: -32 to 32) & $8.11(2.66)$ & $8.80(1.76)$ & $8.26(1.65)$ \\
Scrambled Sentence Test Duration (min) & $8.15(0.87)$ & $8.65(1.31)$ & $7.93(0.92)$ \\
Impossible Tracing Task Duration (min) & $21.80(4.33)$ & $21.63(5.36)$ & $28.55(4.33)$ \\
Typical Exercise Behavior (METS) & $51.95(8.68)$ & $49.65(14.05)$ & $56.68(16.94)$ \\
Planned Exercise Behavior (METS) & $63.79(12.87)$ & $67.10(19.44)$ & $78.79(27.32)$ \\
\hline
\end{tabular}

40 min during the impossible tracing task and were subsequently stopped by the experimenter.

One-way ANOVA on the duration participants persisted on impossible tracing task (hypothesis 1) revealed a trend towards differences between conditions, $F(2,55)=2.66$, $p=.08$, with a medium effect size $\left(\eta_{p}^{2}=.09\right)$. Bayesian analysis, however, indicated the data was 1.06 times more credible under the null than the alternative hypothesis. Post-hoc analysis revealed participants in the neutral condition persisted more than participants in the autonomous motivation condition (28.6 vs. $21.6 \mathrm{~min}, p=.05, d=.63$ ), but Bayesian analyses contrastingly demonstrated weak support for the null hypothesis (data 1.25 times more credible under the null than the alternative hypothesis). Post-hoc analysis also revealed that more participants were required to support the notion that differences exist between the neutral and controlling condition (28.6 vs. $21.8 \mathrm{~min}, p=.06, d=.68$ ). From a Bayesian perspective, data revealed weak support in favor of a difference between the neutral and controlling motivation prime conditions (data 1.10 times more credible under the alternative hypothesis than the null). No significant differences were found between controlling and autonomous conditions (21.8 vs. 21.6 min, $p=.96, d=.05)$, with Bayesian analyses indicating data to be 5.46 times more credible under the null than the alternative hypothesis. One-way ANOVA revealed no significant difference between conditions on planned exercise behavior (hypothesis 2 ), $F(2,55)=.55, p=.58, \eta_{p}^{2}=.02$. From a Bayesian perspective, data was 4.85 times more credible under the null than the alternative hypothesis.

\section{Brief Discussion}

Study 1 did not support our hypothesis that priming autonomous motivation would promote persistence; in fact, our data supports (albeit weakly) the null hypothesis that persistence is indifferent between the autonomous motivation and neutral prime conditions. Furthermore, the direction of the reported effect was opposite to that theorized (participants primed to experience autonomous motivation persisted less than their neutrally primed counterparts, on average). A reduction in persistence is contrary to effects previously reported (Keatley et al. 2014) and other prototypically self-determined responses (e.g., Ntoumanis et al. 2014b; Radel et al. 2009). While priming controlling regulation did elicit expected (although marginally nonsignificant) reductions in persistence relative to the neutral prime, Bayesian evidence for the existence of this effect is weak. This similarity in persistence duration across motivational priming conditions (Autonomous prime: $21.6 \mathrm{~min}$, Controlling prime: $21.8 \mathrm{~min}$ ) was surprising, hence, needs replication. Moreover, it is of interest to explore why the autonomous motivation prime led to a similar behavioral outcome as a controlling motivation prime. That is, despite a similar decreased level of persistence (compared to a neutral prime), was the underlying experience distinct in the autonomous condition and the controlling condition? Our findings also strongly support the null hypothesis that exercise plans would differ across priming conditions. Nonetheless, this outcome is unsurprising given the motivational primes were ineffective in the first phase of the experiment.

\section{Study 2}

Study 1 found weak evidence in support of our hypothesis that priming participants to experience controlling motivation may reduce persistence relative to a neutral prime. Contrary to expectations, however, data supported the null hypothesis that the effect of the autonomous motivation prime on persistence is indifferent to both the controlling motivation and neutral prime. Furthermore, we found exercise plans to be unaffected by priming condition. Study 2 aimed to replicate these findings (hence, hypotheses 1 and 2 were tested again), and additionally investigate whether motivational primes influence engagement quality during the persistence task. More autonomous motivation is characterized by more adaptive responding to setbacks and failures (Legault and Inzlicht 2013). We therefore hypothesized that participants in the autonomous/controlling condition would report greater/less frustration during the tracing task relative to the neutral condition (hypothesis 3). In addition, more autonomous involvement is often associated with a greater intensity of engagement (Banting et al. 2011). Accordingly, the intensity of self-regulatory engagement was measured, in the form of heart rate variability (HRV) and a subjective measure of mental exertion. Increased HRV from baseline is theorized to be reflective of greater self-regulatory engagement because heart rate and top-down self-regulatory activity (i.e., 
pre-frontal cortex activation) are linked via the parasympathetic nervous system (Segerstrom and Nes 2007). Specifically, increased pre-frontal cortex activation is theorized to stimulate parasympathetic nervous system activity, which in turn increases HRV via momentary reductions in heart rate (Holzman and Bridgett 2017). As such, we hypothesized participants in the autonomous/controlling condition would experience greater/ lower increases in HRV (hypothesis 4) and report higher/lower mental exertion (hypothesis 5) during the tracing task relative to the neutral condition. Further methodological changes were made in Study 2 to strengthen conclusions, including measures of task motivation and importance (as possible confounding variables) and a funnel debriefing method. Finally, the typical exercise behavior measure was removed given concerns it may have biased reports of planned exercise behavior.

\section{Methods}

\section{Participants}

Ninety-two participants (Mean age $=19.92, S D=3.87 ; 64$ female) were recruited to this study in the same way as Study 1. Ethical approval was granted by the University Ethics Committee prior to study commencement.

\section{Procedure}

All procedures were identical to Study 1, except for changes listed in the following sections. Upon entering the lab, participants were asked to wear a Polar Heart Rate (HR) monitor (Polar Team Pro, Polar Electro Ltd., Warwick, UK), and informed their HR was being monitored to explore physiological responses to the problem-solving tasks. Participants were asked to sit quietly and still for a period of five minutes. The initial two-minute period was used for HRV stabilization (Flatt and Esco 2016) and the remaining three minutes represented an acceptable period for recording baseline HRV (Laborde et al. 2017). HRV was measured using the root mean square of successive differences (RMSSD), which represents the mean variation in duration between heart beats over a particular temporal period (Laborde et al. 2017). HRV was then recorded throughout the tracing task, and a change score from baseline calculated for use in further analysis.

Participants then completed the BMIS, the practice geometric task, the SST ( $n$ per condition; Aut Mot: 30, Con Mot: 31, Neut: 31), and an additional measure of tracing task importance. During the impossible tracing task, the maximum duration before participants were stopped was extended from forty to forty-five minutes in order to reduce the number of participants stopped by the experimenter. After the tracing task, participants completed measures of mental exertion, task motivation, frustration, and planned exercise behavior. Participants then completed a funneled debriefing method to explore participant suspicion as to the study's true aims (see Chartrand and Bargh 1996). Participants were informed the session was completed and thanked for their participation.

\section{Self-Report Measures}

Mood As in Study 1.

Tracing Task Importance Task importance was measured by participants indicating the extent they agreed with the statement 'This activity is important to me' on a Likert scale ranging from 1 ('corresponds not at all') to 7 ('corresponds exactly').

Mental Effort The Borg scale (Borg 1982) was used to measure mental effort experienced during the impossible tracing task. The original Borg scale has demonstrated good validity (Chen et al. 2002). The scale used in the present study was preceded by the stem: 'How much mental effort did you exert while performing the tracing task?'. Participants rated their mental effort on a scale ranging from 0 ('nothing at all'), to 13 ('absolute maximum').

Task Motivation The Situational Motivation Scale (SIMS; Guay et al. 2000) measured the quality of motivation participants had during the impossible tracing task. The SIMS measures four types of motivation (intrinsic motivation, identified regulation, external regulation, and amotivation) and includes sixteen questions (four questions per motivation type). Each question included the stem 'Please circle the number that best describes the reason why you are currently engaged in this activity'. Participants answered on a Likert scale ranging from 1 ('corresponds not all') to 7 ('corresponds exactly'). This scale has demonstrated satisfactory validity and reliability in previous research (Guay et al. 2000). A self-determination index (SDI) was computed from participants motivation scores in order to reduce the number of variables in analyses. The SDI was calculated using the following formula: $(2 *$ intrinsic $+1 *$ identified $)-(1 *$ external $+2 *$ amotivation $)$. Higher SDI scores reflect increased autonomous engagement.

Frustration Frustration was measured using a modified single item taken from Bray et al. (2008): 'How frustrated did you feel when performing the tracing task?'. Participants rated their frustration on a Likert Scale ranging from 1 ('not at all frustrated') to 7 ('extremely frustrated'). Previous research shows this measure to be sensitive to differences in selfregulatory demands (Bray et al. 2008).

Planned Exercise Behavior. As in Study 1. 
Table. 2 Mean scores of study variables across conditions in Study 2 (95\% confidence interval $[ \pm]$ included in brackets)

\begin{tabular}{lccr}
\hline & $\begin{array}{l}\text { Controlling } \\
\text { Motivation }(n=31)\end{array}$ & $\begin{array}{l}\text { Autonomous } \\
\text { Motivation }(n=30)\end{array}$ & Neutral $(n=31)$ \\
\hline Mood (potential range: -32 to 32) & $8.48(2.13)$ & $9.37(2.21)$ & $9.45(1.65)$ \\
Scrambled Sentence Test Duration (min) & $9.60(0.92)$ & $8.92(0.81)$ & $8.38(0.76)$ \\
Task Importance (potential range: 1 to 7) & $3.74(0.55)$ & $3.47(0.45)$ & $3.93(0.42)$ \\
Impossible Tracing Task Duration (min) & $26.45(2.48)$ & $26.96(2.31)$ & $28.17(2.23)$ \\
HRV Change (from baseline; RMSSD) & $-2.46(4.89)$ & $-0.28(2.74)$ & $1.86(3.26)$ \\
Mental Effort (potential range: 0 to 13) & $6.68(0.36)$ & $7.2(0.49)$ & $7.19(0.43)$ \\
Task Motivation (potential range: -18 to 18) & $2.41(1.56)$ & $3.79(1.68)$ & $3.48(1.68)$ \\
Frustration (potential range: 1 to 7) & $5.29(0.21)$ & $5.03(0.25)$ & $5.26(0.26)$ \\
Planned Exercise Behavior (METS) & $53.77(3.61)$ & $63.3(5.14)$ & $59.81(4.99)$ \\
\hline
\end{tabular}

\section{Results}

All results are displayed in Table 2. Preliminary analyses using one-way ANOVA found no significant differences across conditions for HRV at rest, $F(2,78)=.24, p=.79$; mood, $F(2,89)=.28, p=.76$; tracing task importance, $F(2,88)=.91, p=.41$; motivation, $F(2,88)=.76, p=.47$, and SST duration, $F(2,89)=2.12, p=.13$. Bayesian analyses support these findings, with data 7.68 (HRV at rest), 8.21 (mood), 4.93 (tracing task importance), 5.55 (motivation), and 1.91 (SST duration), more likely under the null compared to the alternative hypothesis. Seventeen participants (18.5\%) persisted for the full $45 \mathrm{~min}$ during the impossible tracing task and were subsequently stopped by the experimenter.

One-way ANOVA across conditions found no significant differences for impossible tracing task duration (hypothesis 1) $F(2,89)=.14, p=.87, \eta_{p}^{2}=.003$, planned exercise behavior (hypothesis 2 ), $F(2,89)=1.09, p=.34, \eta_{p}^{2}=.02$, frustration (hypothesis 3 ), $F(2,89)=0.34, p=.71, \eta_{p}^{2}=.01$, HRV during the impossible tracing task (hypothesis 4 ), $F(2,77)=0.35$, $p=.71, \eta_{p}^{2}=.01$, and mental effort (hypothesis 5), $F(2,89)=.50, p=.61, \eta_{p}^{2}=.01$. Bayesian analyses support this interpretation, with data 9.11 (impossible tracing task duration), 4.32 (planned exercise behavior), 7.80 (frustration), 5.36 (HRV during the impossible tracing task), and 6.90 (mental effort) times more credible under the null compared to the alternative hypothesis.

\section{Brief Discussion}

As in Study 1, Study 2 did not support our hypothesis that priming autonomous motivation would promote greater persistence and exercise plans relative to the controlling motivation prime and neutral prime. Rather, our data provides evidence in favor of the null hypothesis that no differences in persistence exist across conditions. This finding contrasts slightly with Study 1 where data revealed weak evidence that priming controlling motivation hindered persistence relative to a neutral prime. A key focus of Study 2 was to explore whether motivational primes influenced the quality and engagement in a task, even though behavioral differences may not manifest. However, no evidence of this was found. Rather, data indicates that frustration, mental effort, and HRV are unaffected by the priming manipulation. It is possible our priming manipulation was ineffective in creating distinct motivational states. Yet it is notable that our primes share many similarities with previous research demonstrating hypothesized effects (e.g., Brown et al. 2016; Keatley et al. 2014) and so alternative explanations should be given consideration. For instance, motivational priming effects at the population level may be smaller than anticipated (e.g., Weingarten et al. 2016), thus rendering the sample size of this study less able to identify any effect. Alternatively, unanticipated moderators unique to the present studies may have influenced how our prime manifested. We discuss this possibility in the General Discussion below.

\section{Internal Meta-Analysis}

Given arguments that meta-analyzing experimental effects tighten conclusions surrounding the size of an effect (Goh et al. 2016), we estimated the fixed effects of motivational priming on tracing study duration and planned exercise across both experiments. Post-hoc comparison effect sizes of the influence of the motivational primes on tracing task duration and planned exercise behavior were extracted from each study. The effect size for each comparison was weighted based on study sample size, and then combined to form a mean value.

\section{Results}

The autonomous motivation primes influence on tracing task duration was not significantly different to the controlling motivation prime, $p=.85, d=.04,95 \% \mathrm{CI}(-.36, .45)$, or neutral 
prime, $p=.15, d=.30,95 \%$ CI $(-.11, .72)$. The controlling motivation primes influence on tracing task duration was not significantly different to the neutral prime, $p=.10, d=.35$, $95 \%$ CI $(-.06, .77)$.

The autonomous motivation primes influence on planned exercise was not significantly different to the controlling motivation prime, $p=.19, d=.27,95 \% \mathrm{CI}(-.14, .69)$, or neutral prime, $p=.44, d=.16,95 \%$ CI $(-.25, .57)$. The controlling motivation primes influence on planned exercise was also not significantly different to the neutral prime, $p=.19, d=.27$, $95 \% \mathrm{CI}(-.13, .69)$. All the effect sizes obtained in this analysis were small or small-moderate.

\section{General Discussion}

Previous research demonstrates that when individuals are more autonomously regulated during an activity or in pursuit of a goal they will tend to persist amidst difficulties (e.g., Gaudreau et al. 2012; Legault and Inzlicht 2013; Werner et al. 2016). The present research extended this line of research by examining whether priming distinct motivational states would also influence persistence - specifically, whether autonomous motivation and controlling motivation primes would increase and decrease persistence during a task exposing participants to repeated failure, respectively, relative to a neutral prime. Additionally, we examined whether these primes influenced participants exercise plans made after the task, the rationale here being that effective planning often requires self-regulatory resources that the autonomous/ controlling motivation primes may render more/less available (Muraven et al. 2008; Sjåstad and Baumeister 2018). Across both studies, and contrary to expectations, findings indicate it more likely the autonomous motivation and controlling motivation primes exert no influence on persistence and plans to engage in exercise, compared to a neutral prime.

Motivational primes (relative to a neutral prime) were hypothesized to influence persistence because they should influence the quality of motivation for the problem-solving activity and thus the extent to which engagement is inherently valuable to the participant (Ryan and Deci 2017). Indeed, autonomous motivation/controlling motivation primes should, via the mediating influence of distinct motivational states, reduce/increase internal conflict, enhance/diminish vitality, and heighten/hinder participants tendency to use the cognitive, affective, and energetic resources necessary to persist amidst difficulty (Ryan and Deci 2017). Direct evidence supports that motivational primes influence persistence (Keatley et al. 2014; Ntoumanis et al. 2014b; Radel et al. 2009), however, the present research aimed to bolster this evidence because the method used by two of these studies renders it possible identified effects may have manifest via alternative mechanisms (i.e., subtle differences in experimenter behavior across conditions due to being aware of participant condition; Keatley et al. 2014; Ntoumanis et al. 2014b). Despite theory and extant evidence, our findings support the null hypothesis that autonomous motivation and controlling motivation primes elicit no impact on persistence relative to a neutral prime. This is a surprising finding; it not only contrasts with direct support for this effect (Keatley et al. 2014; Ntoumanis et al. 2014b; Radel et al. 2009), it conflicts with much literature showing motivational primes promote theoretically congruent effects (e.g., Banting et al. 2011; Brown et al. 2016). Furthermore, the present research shares many similarities with literature demonstrating motivational priming effects, and cast a large net to capture initially unanticipated manifestations of motivational differences (i.e., investigating quality of engagement), which reduces concerns key methodological decisions explain our null findings. For instance, the scrambled-sentence task used in the present research to prime motivation was similar in length, took a similar duration to complete, and consisted of similar priming words, to previous literature (e.g., Brown et al. 2016; Hodgins et al. 2006, 2007; Keatley et al. 2014). Previous work also demonstrates our persistence measure to be sensitive to motivational primes (e.g., Keatley et al. 2014). In light of these considerations it thus begs the question - why do the findings of the present research depart so starkly from theory and extant literature?

Various explanations are available for the null findings in the present research, not least that situational conditions or participant characteristics unique to the present study's may have extinguished the effect or rendered it too small to identify. While the notion that motivational priming effects can be reversed or extinguished by particular contextual or participant factors is not frequently noted in extant motivational priming literature (thus informing the design of the present research not to give due consideration to moderation effects; e.g., Hodgins et al. 2006), Cesario (2014) maintains the assumption that priming effects are invariant across contexts and populations is 'inconsistent with what is known about the evolved, computational nature of the mind' (Cesario 2014, p. 41). There is some support for the idea that contextual and/or population characteristics may specifically reverse or eliminate motivational priming effects, for instance, a controlling motivation prime (compared to an autonomous motivation and neutral prime) was found to promote persistence during a problem-solving task (the reverse effect to that hypothesized in the present research), but only for individuals high in attachment anxiety (Milyavskaya et al. 2012). Also, individuals chronically high in autonomous and controlling motivation were found to be insensitive to autonomous motivation and controlling motivation primes, respectively, purportedly due to ceiling effects (Levesque and Pelletier 2003, Study 4). Although it remains unknown what specific contextual or participant factors in the present research would have moderated motivational priming effects to become non-existent or too 
small to measure (particularly given there was no clear methodological departure from past literature demonstrating an effect), we cannot discount that even small or seemingly inconsequential factors unique the present research may have rendered our null findings. However, if small methodological factors can so easily produce null or contrary results, it is important to note it would challenge the credibility of extant motivational priming literature that give minimal or no consideration to moderation influences but nonetheless find expected effects (e.g., Hodgins et al. 2006; Radel et al. 2009).

Another likely explanation for our findings, which again may implicate the credibility of extant motivational priming literature, is insufficient statistical power to identify motivational priming effects at the population level. The motivational primes used in the present research were expected to exert a large effect due to prior literature demonstrating similar effect magnitudes (e.g., Keatley et al. 2014). However, in hindsight, an effect of this magnitude may well be unlikely at the population level. Indeed, most behavioral priming effects tend to be of a small-to-medium magnitude (Weingarten et al. 2016), although it should be noted that effects from motivational priming literature are on average medium in magnitude (e.g., Banting et al. 2011; Radel et al. 2009; Scarapicchia et al. 2013), but can range from small (e.g., Banting et al. 2011) to very large (e.g., Keatley et al. 2014). If motivational priming effects do exist at the population level at a small or medium magnitude, the probability that the present research (with a combined sample of 150 participants, and an alpha level of .05 ) would not identify its existence is $82 \%$ and $22 \%$, respectively. Accordingly, it represents a distinct possibility that the null findings in the present research simply reflect a type 2 error. Considering this possibility, it would again shift a critical gaze on to extant motivational priming literature. This literature often finds priming effects small or medium in magnitude with suboptimal statistical power (e.g., Hodgins et al. 2006). Failed replications in general priming literature have led authors to acknowledge the possibility that questionable research practices may explain positive findings from past research (e.g., Shanks et al. 2013). We similarly suggest that the use of questionable research practices would help explain the consistency in which motivational priming effects are found with statistical power that is inadequate or would be inadequate if motivational priming effect at the population level are smaller than anticipated.

No evidence was available showing our motivational primes gave rise to distinct motivational states. It is therefore unsurprising that we did not find any differences in plans to engage in exercise after the persistence-requiring task. We hypothesized this process because autonomous involvement in an activity (i.e., our persistence task in this instance) has been shown to be less cognitive depleting, hence, more resources should be available to subsequently plan (Sjåstad and Baumeister 2018). Our null findings also contrast with research demonstrating direct effects of motivational priming on subsequent planning (Banting et al. 2011). Overall, however, our data supports neither the indirect process nor direct effects outlined above. Echoing the explanations for why we found no differences in persistence across conditions, this may be due to unanticipated moderating influences or type 2 error. However, notwithstanding the underlying theory supporting this effect, as well a previous literature, one should not discount that this effect may not exist. In looking more closely at past research, while an autonomous motivation prime has been shown to cause individuals to plan exercise of an elevated frequency (Banting et al. 2011), in other research this prime promoted how long individuals planned to exercise for (but not exercise frequency, which was also measured; Magaraggia et al. 2014), or exerted no effect on exercise plans whatsoever (Brown et al. 2016). This lack of consistency in hindsight offers little support for underlying theory. It is also possible that any priming effect may have been overshadowed by prior exercise habits. Individuals often engage in routinised exercise programs that are resistant to change, even in a cognitively depleted state (stemming from the persistence task). This effect may explain why novel exercise plans not derived from habits or routines may be more susceptible to priming effects (Magaraggia et al. 2014).

\section{Limitations and Future Directions}

There is a distinct possibility that the magnitude of motivational priming effects may be smaller than initially thought (e.g., Weingarten et al. 2016). Thus, future research should aim to achieve high statistical power (particularly by recruiting more participants) to find small effects - that is, if small effects are believed by authors to be of some practical importance. Relatedly, researchers should aim to preregister their studies to improve their study's credibility. Given no motivational priming research has yet been pre-registered, and concerns exist in relation to the possible use of questionable research practices in priming literature, pre-registration would represent a major step forward in improving the quality of research in this field.

Where words are used to prime distinct motivational states, future research may benefit from ensuring all participants are familiar with such words. Indeed, in instances where a priming word is not fully understood it would not be expected to elicit a priming influence. Although it is expected that the priming words used in the present research were understood by all participants, it yet cannot be ruled out that some difficulties in priming word comprehension arose. Future research may also benefit from implementing primes that are of a higher dosage or duration (Cesario 2014; Weingarten et al. 2016), or oriented specifically towards task engagement. Motivational concepts are predominantly accessed in the service of task engagement (e.g., increased persistence, task performance; Ntoumanis et al. 2014b; Radel et al. 2009), as opposed to task disengagement, yet the link between motivation 
and specific task engagement can be made more explicit. For instance, watching a video (purportedly as part of an unrelated study) showing an actor detailing task engagement to be important, challenging, and enjoyable (i.e., the prime used in Ntoumanis et al. 2014b) may lead to greater persistence, compared to a SST prime, in which the words are not directly related to task engagement.

It is likely that individuals with rigid exercise routines will be less susceptible to the influence of distinct motivational states (Rebar et al. 2014). To overcome the influence of habitual behaviors, future research should look to explore how motivational primes influence individuals that vary considerably in their exercise plans or study this phenomena with respect to novel behaviors. Because novel behaviors and their motivational foundation are not robust, plans may be heavily informed by variable motivational inputs. Finally, many failed attempts at replicating priming effects reflect the influence of minor differences within the experimental setting, rather than the absence of an effect (Cesario 2014). The minor adjustments we made, such as experimenter blinding, may be highly influential for study outcomes and likely to be very impactful on how an effect manifests (Doyen et al. 2012; Gilder and Heerey 2018). Future research, where possible, should attempt identical, rather than conceptual, replications of motivational priming.

\section{Conclusion}

This research provides evidence that priming autonomous/ controlling motivation exerts no influence on persistence or plans to engage in exercise (relative to a neutral prime), thus conflicting with extant theory and evidence. Numerous explanations exist for these null findings. These include unanticipated moderating factors unique to the present research, and that motivational priming effects are smaller than anticipated (thus preventing the ability of our research to identify these effects). Future research should seek to implement preregistration and conduct research capable of identifying small motivational priming effects.

Author Contribution SM recruited and tested participants, and drafted the manuscript. SM and IT were both involved in the conception and design of the study, data analysis, and critical revision of the manuscript. Both authors approved the final version of the paper.

Funding Information Open Access funding provided by Projekt DEAL.

\section{Compliance with Ethical Standards}

Declaration of Conflicting Interests The authors declared no potential conflicts of interest with respect to the research, authorship, and/or publication of this article.

Conflicts of interest: none.
Open Access This article is licensed under a Creative Commons Attribution 4.0 International License, which permits use, sharing, adaptation, distribution and reproduction in any medium or format, as long as you give appropriate credit to the original author(s) and the source, provide a link to the Creative Commons licence, and indicate if changes were made. The images or other third party material in this article are included in the article's Creative Commons licence, unless indicated otherwise in a credit line to the material. If material is not included in the article's Creative Commons licence and your intended use is not permitted by statutory regulation or exceeds the permitted use, you will need to obtain permission directly from the copyright holder. To view a copy of this licence, visit http://creativecommons.org/licenses/by/4.0/.

\section{References}

Banting, L. K., Dimmock, J. A., \& Grove, J. R. (2011). The impact of automatically activated motivation on exercise-related outcomes. Journal of Sport and Exercise Psychology, 33, 569-585. https:// doi.org/10.1123/jsep.33.4.569.

Bargh, J, A. (2013). Social psychology and the unconscious: The automaticity of higher mental processes. Psychology Press. Retrieved from: https://www.taylorfrancis.com/books/9781134954100

Baumeister, R. F., Bratslavsky, E., Muraven, M., \& Tice, D. M. (1998). Ego depletion: Is the active self a limited resource? Journal of Personality and Social Psychology, 74, 1252-1265. https://doi. org/10.1037/0022-3514.74.5.1252.

Berkman, E, T., Kahn, L, E., \& Livingston, J, L. (2016). Valuation as a mechanism of self-control and ego depletion. In Self-regulation and ego control (pp. 255-279). doi: https://doi.org/10.1016/B978-0-12801850-7.00013-5.

Berkman, E. T., Hutcherson, C. A., Livingston, J. L., Kahn, L. E., \& Inzlicht, M. (2017). Self-control as value-based choice. Current Directions in Psychological Science, 26, 422-428. https://doi.org/ 10.1177/0963721417704394.

Borg, G. A. (1982). Psychophysical bases of perceived exertion. Medicine and Science in Sports and Exercise, 14, 377-381 Retrieved from: http://fcesoftware.com/images/15_Perceived_ Exertion.pdf.

Bray, S. R., Martin Ginis, K. A., Hicks, A. L., \& Woodgate, J. (2008). Effects of self-regulatory strength depletion on muscular performance and EMG activation. Psychophysiology, 45, 337-343. https://doi.org/10.1111/j.1469-8986.2007.00625.x.

Brown, D. M., Teseo, A. J., \& Bray, S. R. (2016). Effects of autonomous motivational priming on motivation and affective responses towards high-intensity interval training. Journal of Sports Sciences, 34, 1491-1499. https://doi.org/10.1080/02640414.2015.1119301.

Cameron, C. D., Brown-Iannuzzi, J. L., \& Payne, B. K. (2012). Sequential priming measures of implicit social cognition: A metaanalysis of associations with behavior and explicit attitudes. Personality and Social Psychology Review, 16, 330-350. https:// doi.org/10.1177/1088868312440047.

Cappelli, D. P., \& Mobley, C. C. (2017). Association between sugar intake, Oral health, and the impact on overall health: Raising public awareness. Current Oral Health Reports, 4, 176-183. https://doi. org/10.1007/s40496-017-0142-2.

Cesario, J. (2014). Priming, replication, and the hardest science. Perspectives on Psychological Science, 9, 40-48. https://doi.org/ $10.1177 / 1745691613513470$.

Chartrand, T. L., \& Bargh, J. A. (1996). Automatic activation of impression formation and memorization goals: Nonconscious goal priming reproduces effects of explicit task instructions. Journal of 
Personality and Social Psychology, 71, 464-478 Retrieved from: http://psycnet.apa.org/buy/1996-01799-004.

Chen, M. J., Fan, X., \& Moe, S. T. (2002). Criterion-related validity of the Borg ratings of perceived exertion scale in healthy individuals: A meta-analysis. Journal of Sports Sciences, 20, 873-899. https://doi. org/10.1080/026404102320761787.

Doyen, S., Klein, O., Pichon, C. L., \& Cleeremans, A. (2012). Behavioral priming: it's all in the mind, but whose mind? PLoS One, 7, e29081. https://doi.org/10.1371/journal.pone.0029081.

Duckworth, A. L., Peterson, C., Matthews, M. D., \& Kelly, D. R. (2007). Grit: Perseverance and passion for long-term goals. Journal of Personality and Social Psychology, 92, 1087-1101. https://doi. org/10.1037/0022-3514.92.6.1087.

Faul, F., Erdfelder, E., Lang, A. G., \& Buchner, A. (2007). G* power 3: A flexible statistical power analysis program for the social, behavioral, and biomedical sciences. Behavior Research Methods, 39, 175-191. https://doi.org/10.3758/BF03193146.

Flatt, A. A., \& Esco, M. R. (2016). Heart rate variability stabilization in athletes: Towards more convenient data acquisition. Clinical Physiology and Functional Imaging, 36, 331-336. https://doi.org/ 10.1111/cpf.12233.

Gaudreau, P., Carraro, N., \& Miranda, D. (2012). From goal motivation to goal progress: The mediating role of coping in the selfconcordance model. Anxiety, Stress \& Coping, 25, 507-528. https://doi.org/10.1080/10615806.2011.628015.

Gilder, T. S., \& Heerey, E. A. (2018). The role of experimenter belief in social priming. Psychological Science, 29, 403-417. https://doi.org/ 10.1177/0956797617737128.

Godin, G., \& Shephard, R. J. (1985). A simple method to assess exercise behavior in the community. Can J Appl Sport Sci, 10, 141-146 Retrieved from: https://s3.amazonaws.com/academia.edu. documents/38737335/CJASS-1985.pdf?AWSAccessKeyId= AKIAIWOWYY GZ2Y 53 UL 3 A \& Expires $=15415901$ $20 \&$ Signature $=w 04 w 40 Y E d w E O b O K R g O K r N A a 9 j y Y \%$ 3D\&response-content-disposition=inline $\% 3 \mathrm{~B} \% 20$ filename $\% 3 \mathrm{DA}$ simple method to assess exercise behav.pdf.

Goh, J. X., Hall, J. A., \& Rosenthal, R. (2016). Mini meta-analysis of your own studies: Some arguments on why and a primer on how. Social and Personality Psychology Compass, 10, 535-549. https:// doi.org/10.1111/spc3.12267.

Guay, F., Vallerand, R. J., \& Blanchard, C. (2000). On the assessment of situational intrinsic and extrinsic motivation: The situational motivation scale (SIMS). Motivation and Emotion, 24, 175-213. https:// doi.org/10.1023/A:1005614228250.

Hagger, M. S., Wood, C., Stiff, C., \& Chatzisarantis, N. L. (2010). Ego depletion and the strength model of self-control: A meta-analysis. Psychological Bulletin, 136, 495-525. https://doi.org/10.1037/ a0019486.

Harris, C. R., Coburn, N., Rohrer, D., \& Pashler, H. (2013). Two failures to replicate high-performance-goal priming effects. PLoS One, 8 , e72467. https://doi.org/10.1371/journal.pone.0072467.

Hauser, D. J., Ellsworth, P. C., \& Gonzalez, R. (2018). Are manipulation checks necessary? Frontiers in psychology, 9, 1-10. https://doi.org/ 10.3389/\%2Ffpsyg.2018.00998.

Heaven, P. C., \& Ciarrochi, J. (2008). Parental styles, conscientiousness, and academic performance in high school: A three-wave longitudinal study. Personality and Social Psychology Bulletin, 34, 451-461. https://doi.org/10.1177/0146167207311909.

Hodgins, H. S., Yacko, H. A., \& Gottlieb, E. (2006). Autonomy and nondefensiveness. Motivation and Emotion, 30, 283-293. https:// doi.org/10.1007/s11031-006-9036-7.

Hodgins, H. S., Brown, A. B., \& Carver, B. (2007). Autonomy and control motivation and self-esteem. Self and Identity, 6, 189-208. https://doi.org/10.1080/15298860601118769.

Hodgins, H. S., Weibust, K. S., Weinstein, N., Shiffman, S., Miller, A., Coombs, G., \& Adair, K. C. (2010). The cost of self-protection:
Threat response and performance as a function of autonomous and controlled motivations. Personality and Social Psychology Bulletin, 36, 1101-1114. https://doi.org/10.1177/0146167210375618.

Holzman, J. B., \& Bridgett, D. J. (2017). Heart rate variability indices as bio-markers of top-down self-regulatory mechanisms: A metaanalytic review. Neuroscience \& Biobehavioral Reviews, 74, 233 255. https://doi.org/10.1016/j.neubiorev.2016.12.032.

Jõesaar, H., Hein, V., \& Hagger, M. S. (2011). Peer influence on young athletes' need satisfaction, intrinsic motivation and persistence in sport: A 12-month prospective study. Psychology of Sport and Exercise, 12, 500-508. https://doi.org/10.1016/j.psychsport.2011. 04.005 .

Keatley, D. A., Clarke, D. D., Ferguson, E., \& Hagger, M. S. (2014). Effects of pretesting implicit self-determined motivation on behavioral engagement: Evidence for the mere measurement effect at the implicit level. Frontiers in Psychology, 5, 125. https://doi.org/10. 3389/fpsyg.2014.00125.

Laborde, S., Mosley, E., \& Thayer, J. F. (2017). Heart rate variability and cardiac vagal tone in psychophysiological researchrecommendations for experiment planning, data analysis, and data reporting. Frontiers in Psychology, 8, 213. https://doi.org/10.3389/ fpsyg.2017.00213.

Legault, L., \& Inzlicht, M. (2013). Self-determination, self-regulation, and the brain: Autonomy improves performance by enhancing neuroaffective responsiveness to self-regulation failure. Journal of Personality and Social Psychology, 105, 123-138. https://doi.org/ 10.1037/a0030426.

Levesque, C., \& Pelletier, L. G. (2003). On the investigation of primed and chronic autonomous and heteronomous motivational orientations. Personality and Social Psychology Bulletin, 29, 1570-1584. https://doi.org/10.1177/0146167203256877.

Levesque, C., Copeland, K. J., \& Sutcliffe, R. A. (2008). Conscious and nonconscious processes: Implications for self-determination theory. Canadian Psychology/Psychologie Canadienne, 49, 218-224. https://doi.org/10.1037/a0012756.

Lyu, R. W., Lai, C., \& Liu, J. (2017). The role of ego depletion in goal pursuit: A construal-level perspective. Social Behavior and Personality: An International Journal, 45, 1143-1156. https://doi. org/10.2224/sbp.6337.

Magaraggia, C., Dimmock, J., \& Jackson, B. (2014). Motivational priming as a strategy for maximising exercise outcomes: Effects on exercise goals and engagement. Journal of Sports Sciences, 32, 826835. https://doi.org/10.1080/02640414.2013.862841.

Marlatt, G. A., \& Donovan, D. M. (Eds.). (2005). Relapse prevention: Maintenance strategies in the treatment of addictive behaviors. Guilford press. Retrieved from: https://books.google.co.uk/books? $\mathrm{hl}=$ en\&lr=\&id=Sj-NZMIF-QcC\&oi=fnd \&pg=PA1\&dq=Relapse+ prevention:+Maintenance+strategies+in+the+treatment+of+ addictive +behaviors \& ots $=1$ Q Sw m T 4 CXY \& sig $=$ 33RWiBtlXRfLbNbTX5w1LkKjaS8\#v=onepage \&q=Relapse\% 20 prevention $\% 3 \mathrm{~A} \% 20$ Maintenance $\% 20$ strategies $\% 20$ in $\% 20$ the $\%$ 20 treatment $\% 20 \mathrm{of} \% 20$ addictive $\% 20$ behaviors $\& \mathrm{f}=$ false.

Mayer, J. D., \& Gaschke, Y. N. (1988). The experience and metaexperience of mood. Journal of Personality and Social Psychology, 55, 102-111 Retrieved from: http://psycnet.apa.org/ buy/1988-28581-001.

Milyavskaya, M., \& Koestner, R. (2011). Psychological needs, motivation, and well-being: A test of self-determination theory across multiple domains. Personality and Individual Differences, 50, 387-391. https://doi.org/10.1016/j.paid.2010.10.029.

Milyavskaya, M., McClure, M. J., Ma, D., Koestner, R., \& Lydon, J. (2012). Attachment moderates the effects of autonomy-supportive and controlling interpersonal primes on intrinsic motivation. Canadian Journal of Behavioural Science/Revue canadienne des sciences du comportement, 44, 278-287. https://doi.org/10.1037/ a0025828. 
Milyavskaya, M., Inzlicht, M., Hope, N., \& Koestner, R. (2015). Saying "no" to temptation: Want-to motivation improves self-regulation by reducing temptation rather than by increasing self-control. Journal of Personality and Social Psychology, 109, 677-693. https://doi. org/10.1037/pspp0000045.

Moffitt, T. E., Arseneault, L., Belsky, D., Dickson, N., Hancox, R. J., Harrington, H., et al. (2011). A gradient of childhood self-control predicts health, wealth, and public safety. Proceedings of the National Academy of Sciences, 108, 2693-2698. https://doi.org/10. 1073/pnas.1010076108.

Moller, A. C., Deci, E. L., \& Ryan, R. M. (2006). Choice and ego-depletion: The moderating role of autonomy. Personality and Social Psychology Bulletin, 32, 1024-1036. https://doi.org/10.1177/ 0146167206288008.

Muraven, M., Gagné, M., \& Rosman, H. (2008). Helpful self-control: Autonomy support, vitality, and depletion. Journal of Experimental Social Psychology, 44, 573-585. https://doi.org/10. 1016/j.jesp.2007.10.008.

Ntoumanis, N., Edmunds, J., \& Duda, J. L. (2009). Understanding the coping process from a self-determination theory perspective. British journal of health psychology, 14, 249-260. https://doi.org/10.1348/ 135910708 X349352.

Ntoumanis, N., Healy, L. C., Sedikides, C., Smith, A. L., \& Duda, J. L. (2014a). Self-regulatory responses to unattainable goals: The role of goal motives. Self and Identity, 13, 594-612. https://doi.org/10. 1080/15298868.2014.889033.

Ntoumanis, N., Healy, L. C., Sedikides, C., Duda, J., Stewart, B., Smith, A., \& Bond, J. (2014b). When the going gets tough: The "why" of goal striving matters. Journal of Personality, 82, 225-236. https:// doi.org/10.1111/jopy.12047.

Pelletier, L. G., Fortier, M. S., Vallerand, R. J., \& Briere, N. M. (2001). Associations among perceived autonomy support, forms of self-regulation, and persistence: A prospective study. Motivation and Emotion, 25, 279-306. https://doi.org/10.1023/A:1014805132406.

Quintana, D. S., \& Williams, D. R. (2018). Bayesian alternatives for common null-hypothesis significance tests in psychiatry: A nontechnical guide using JASP. BMC Psychiatry, 18, 178. https://doi. org/10.1186/s12888-018-1761-4.

Radel, R., Sarrazin, P., \& Pelletier, L. (2009). Evidence of subliminally primed motivational orientations: The effects of unconscious motivational processes on the performance of a new motor task. Journal of Sport and Exercise Psychology, 31, 657-674. https://doi.org/10. 1123/jsep.31.5.657.

Rebar, A. L., Elavsky, S., Maher, J. P., Doerksen, S. E., \& Conroy, D. E. (2014). Habits predict physical activity on days when intentions are weak. Journal of Sport and Exercise Psychology, 36, 157-165. https://doi.org/10.1123/jsep.2013-0043.

Rebar, A. L., Dimmock, J. A., Rhodes, R. E., \& Jackson, B. (2018). A daily diary approach to investigate the effect of ego depletion on intentions and next day behavior. Psychology of Sport and Exercise, 39, 38-44. https://doi.org/10.1016/j.psychsport.2018.07.010.

Ryan, R. M., \& Deci, E. L. (2017). Self-determination theory: Basic psychological needs in motivation, development, and wellness. Guilford Publications. Retrieved from: https://books.google.co.uk/ books?hl=en\&lr=\&id=GF0ODQAAQBAJ\&oi=fnd \&pg=PP1\&dq= Self-determination+theory:+Basic+psychological+needs + in + motivation, +development, +and +wellness \& ots $=$ KRGeKqL8sg\&sig=M0zhMNerfzsEVgbhnZHBu21FzCI\#v= onepage \&q=Self-determination $\% 20$ theory $\% 3 \mathrm{~A} \% 20 \mathrm{Basic} \%$ 20 psychological $\% 20$ needs $\% 20$ in $\% 20$ motivation $\% 2 \mathrm{C} \%$ 20development $\% 2 \mathrm{C} \% 20$ and $\% 20$ wellness $\& \mathrm{f}=$ false.
Sallis, J. F., Bull, F., Guthold, R., Heath, G. W., Inoue, S., Kelly, P., et al. (2016). Progress in physical activity over the Olympic quadrennium. The Lancet, 388, 1325-1336. https://doi.org/10.1016/S01406736(16)30581-5.

Scarapicchia, T. M., Sabiston, C. M., Andersen, R. E., \& Bengoechea, E. G. (2013). The motivational effects of social contagion on exercise participation in young female adults. Journal of Sport and Exercise Psychology, 35, 563-575. https://doi.org/10.1123/jsep.35.6.563.

Segerstrom, S. C., \& Nes, L. S. (2007). Heart rate variability reflects selfregulatory strength, effort, and fatigue. Psychological Science, 18, 275-281. https://doi.org/10.1111/j.1467-9280.2007.01888.x.

Shanks, D. R., Newell, B. R., Lee, E. H., Balakrishnan, D., Ekelund, L., Cenac, Z., Kavvadia, F., \& Moore, C. (2013). Priming intelligent behavior: An elusive phenomenon. PLoS One, 8, e56515. https:// doi.org/10.1371/journal.pone.0056515.

Simmons, J. P., Nelson, L. D., \& Simonsohn, U. (2012). A 21 word solution. Dialogue: The Official Newsletter of the Society for Personality and Social Psychology, 26, 4-7. https://doi.org/10. 2139/ssrn.2160588.

Sjåstad, H., \& Baumeister, R. F. (2018). The future and the will: Planning requires self-control, and ego depletion leads to planning aversion. Journal of Experimental Social Psychology, 76, 127-141. https:// doi.org/10.1016/j.jesp.2018.01.005.

Smith, A. L., Ntoumanis, N., Duda, J. L., \& Vansteenkiste, M. (2011). Goal striving, coping, and well-being: A prospective investigation of the self-concordance model in sport. Journal of Sport and Exercise Psychology, 33, 124-145. https://doi.org/10.1123/jsep.33. 1.124.

Srull, T. K., \& Wyer, R. S. (1979). The role of category accessibility in the interpretation of information about persons: Some determinants and implications. Journal of Personality and Social Psychology, 37, 1660-1672 Retrieved from: http://psycnet.apa.org/record/198101290-001.

Vallerand, R. J., Fortier, M. S., \& Guay, F. (1997). Self-determination and persistence in a real-life setting: Toward a motivational model of high school dropout. Journal of Personality and Social Psychology, 72, 1161-1176. https://doi.org/10.1037/0022-3514.72.5.1161.

Wagenmakers, E. J., Love, J., Marsman, M., Jamil, T., Ly, A., Verhagen, J., et al. (2018). Bayesian inference for psychology. Part II: Example applications with JASP. Psychonomic bulletin \& review, 25, 58-76. https://doi.org/10.3758/s13423-017-1323-7.

Weingarten, E., Chen, Q., McAdams, M., Yi, J., Hepler, J., \& Albarracín, D. (2016). From primed concepts to action: A meta-analysis of the behavioral effects of incidentally presented words. Psychological Bulletin, 142, 472-497. https://doi.org/10.1037/bul0000030.

Weinstein, N., \& Hodgins, H. S. (2009). The moderating role of autonomy and control on the benefits of written emotion expression. Personality and Social Psychology Bulletin, 35, 351-364. https:// doi.org/10.1177/0146167208328165.

Weinstein, N., Hodgins, H. S., \& Ryan, R. M. (2010). Autonomy and control in dyads: Effects on interaction quality and joint creative performance. Personality and Social Psychology Bulletin, 36, 1603-1617. https://doi.org/10.1177/0146167210386385.

Werner, K. M., Milyavskaya, M., Foxen-Craft, E., \& Koestner, R. (2016). Some goals just feel easier: Self-concordance leads to goal progress through subjective ease, not effort. Personality and Individual Differences, 96, 237-242. https://doi.org/10.1016/j.paid.2016.03. 002.

Publisher's Note Springer Nature remains neutral with regard to jurisdictional claims in published maps and institutional affiliations. 